\title{
Teores nutricionais em folhas e frutos de figueira, submetida a épocas de poda e irrigação
}

\section{The nutritional levels in leaves and fruits of fig trees as a function of pruning time and irrigation}

\author{
Sarita Leonel ${ }^{1 *}$; Marco Antonio Tecchio ${ }^{2}$
}

\section{Resumo}

O trabalho teve como objetivo avaliar os teores nutricionais foliares e nos frutos de figueira 'Roxo de Valinhos', podada em diferentes épocas, correspondentes aos meses de julho, agosto, setembro e outubro dos anos de 2004 e 2005, com e sem o uso de irrigação, no município de Botucatu/SP. Para atingir tal objetivo adotou-se um delineamento experimental em parcelas subdivididas, com 5 repetições em blocos, onde as parcelas corresponderam aos tratamentos com e sem irrigação e as subparcelas foram constituídas pelas podas realizadas nos quatro meses do ano. Foram avaliados os teores de $\mathrm{N}, \mathrm{P}, \mathrm{K}, \mathrm{Ca}, \mathrm{Mg}, \mathrm{S}, \mathrm{B}, \mathrm{Cu}, \mathrm{Fe}, \mathrm{Mn}$ e $\mathrm{Zn}$ em folhas e frutos nos dois ciclos agrícolas. Os resultados evidenciaram que não houve diferenças significativas entre os teores de macro e micronutrientes nas folhas nos tratamentos com e sem irrigação no ciclo 2004/05, com exceção do cobre, onde o tratamento com irrigação apresentou o maior teor do nutriente $\left(6 \mathrm{mg} \mathrm{kg}^{-1}\right)$. Nos frutos, não houve diferenças, com exceção do Zn, que também apresentou os maiores teores $\left(28 \mathrm{mg} \mathrm{kg}^{-1}\right)$, no tratamento com irrigação. No ciclo agrícola 2005/06 houve diferenças para o $\mathrm{N}\left(40 \mathrm{~g} \mathrm{~kg}^{-1}\right)$ e o K $\left(20 \mathrm{~g} \mathrm{~kg}^{-1}\right)$ nas folhas, cujos maiores teores foram verificados no tratamento com irrigação. Nos frutos, o $\mathrm{N}$ apresentou diferença significativa e o maior teor foi observado sem irrigação $\left(21 \mathrm{~g} \mathrm{~kg}^{-1}\right)$. Em relação aos meses de poda, foram verificadas diferenças significativas para os teores de $\mathrm{Ca}, \mathrm{Fe}$ e $\mathrm{Zn}$ nas folhas e $\mathrm{Ca}, \mathrm{K}, \mathrm{Mg}, \mathrm{S}$ e $\mathrm{Zn}$ nos frutos no ciclo agrícola 2004/05. No ciclo 2005/06 não houve diferenças entre os teores foliares dos nutrientes avaliados e nos frutos houve diferença para o $\mathrm{N}, \mathrm{Ca}$ e $\mathrm{Cu}$.

Palavras-chave: Ficus carica L, nutrição.

\begin{abstract}
The present study aimed to evaluating the nutritional content in leaves and fruits of the fig tree 'Roxo de Valinhos', pruned at different periods corresponding to the months of July, August, September and October in the years of 2004 and 2005, with and without the use of irrigation, in the county of Botucatu, São Paulo State, Brazil. To achieve this objective, the adopted experimental design was in blocks with subdivided plots and 5 replications, in which plots corresponded to treatments with and without irrigation and subplots included prunings done in the above-mentioned four months. The levels of $\mathrm{N}, \mathrm{P}$, $\mathrm{K}, \mathrm{Ca}, \mathrm{Mg}, \mathrm{S}, \mathrm{B}, \mathrm{Cu}, \mathrm{Mn}$ and $\mathrm{Zn}$ in leaves and fruits were evaluated in the two crop cycles. The results indicated no significant differences among macro and micronutrient levels in the leaves subjected to treatments with and without irrigation in the cycle 2004/05, except for cupper which showed higher level with the treatment including irrigation $\left(6 \mathrm{mg} \mathrm{kg}^{-1}\right)$. In the fruits, there was no difference, except for $\mathrm{Zn}$, which also showed the highest levels $\left(28 \mathrm{mg} \mathrm{kg}^{-1}\right)$ with irrigation. In the crop cycle 2005/06, there
\end{abstract}

\footnotetext{
1 Engenheira Agrônoma. Professor Adjunto. UNESP. Faculdade de Ciências Agronômicas. Departamento de Produção Vegetal/ Horticultura. Botucatu/SP. E-mail: sarinel@fca.unesp.br

2 Engenheiro Agrônomo. Pesquisador Científico. Centro Avançado de Pesquisa Tecnológica do Agronegócio de Frutas - Instituto Agronômico de Campinas-Jundiaí-SP. E-mail: tecchio@iac.sp.gov.br

* Autor para correspondência
} 
were differences for $\mathrm{N}\left(40 \mathrm{~g} \mathrm{~kg}^{-1}\right)$ and $\mathrm{K}\left(20 \mathrm{~g} \mathrm{~kg}^{-1}\right)$ in the leaves, where the highest levels were observed with the treatment including irrigation. In the fruits, $\mathrm{N}$ had significant difference and its highest level was observed without irrigation $\left(21 \mathrm{~g} \mathrm{~kg}^{-1}\right)$. In relation to the pruning periods, significant differences were observed for $\mathrm{Ca}, \mathrm{Fe}$ and $\mathrm{Zn}$ content in the leaves and $\mathrm{Ca}, \mathrm{K}, \mathrm{Mg}, \mathrm{S}$ and $\mathrm{Zn}$ content in the fruits in the crop cycle 2004/05. In the cycle 2005/06, there were not differences among the levels of the evaluated nutrients in the leaves, and in the fruits there was difference for $\mathrm{N}, \mathrm{Ca}$ and $\mathrm{Cu}$.

Key words: Ficus carica L, nutrition

\section{Introdução}

Sobre a necessidade de realização da prática da poda na cultura da figueira, Corrêa e Santos (1999) reportam que os cultivos comerciais no Brasil se estabeleceram a partir do início do século 20 e a planta era muita atacada por brocas e ferrugem, que prejudicavam o desenvolvimento das mesmas, dando origem a frutos pequenos e atrofiados, cuja colheita anual nunca ultrapassava o mês de janeiro (RIGITANO, 1964). Visando solucionar o problema, teve início a poda drástica, com destruição dos ramos podados (CORRÊA; SANTOS, 1999). Segundo Maiorano et al. (1997), a figueira é uma planta que se adapta muito bem ao sistema de poda drástica ou enérgica, fazendo com que as plantas permaneçam em estado arbustivo.

Com a formação da planta, anualmente executa-se a poda de frutificação. De acordo com a recomendação de Penteado e Franco (1997), o melhor período para a sua realização, considerandose apenas a produção de frutos, é de junho a julho. Porém, com intuito de acelerar ou retardar a época da colheita no Estado de São Paulo, a figueira pode ser podada de maio a novembro, em função das condições climáticas e do local de cultivo. A planta podada nesses períodos pode ter sua produção afetada quanto à quantidade e qualidade, porém com vantagens econômicas, possibilitando a venda do produto final com preços mais atrativos, uma vez que o mesmo é vendido na entressafra dos mercados tradicionais.

De acordo com Antunes, Abrahão e Silva (1997), a figueira adapta-se melhor em regiões onde o inverno é suficientemente frio e a estação de crescimento é longa, com calor e luz abundantes, chuvas bem distribuídas e umidade atmosférica baixa. Para os autores, nas condições do Estado de São Paulo, de maneira geral, as precipitações pluviométricas são suficientes para o desenvolvimento da figueira. No entanto, a irrigação pode ser utilizada, com vantagens, nos períodos de estiagem, como corretivo da má distribuição das chuvas, e principalmente, quando se deseja a antecipação da colheita, para alcançar preços mais competitivos no mercado.

As exigências nutricionais para a cultura da figueira são pouco conhecidas. Os resultados disponíveis em sua grande maioria versam sobre o uso de adubações orgânicas, como práticas favoráveis, tanto no desenvolvimento como na produção. Alguns experimentos com fontes e níveis de nutrientes, principalmente nitrogênio já foram conduzidos, no entanto, pouco se sabe sobre a necessidade dos demais nutrientes. De acordo com Penteado (1986), adubações equilibradas e satisfatórias durante a fase de formação e produtiva da planta são condicionantes de boas safras.

A absorção de nutrientes minerais pela figueira varia em função dos estados fisiológicos da planta durante o ciclo de produção (FERNANDES; BUZETTI, 1999). Proebsting e Warner (1954) avaliando os teores de N, P, K, Ca e Mg em folhas de figueira coletadas entre os meses de abril a setembro, verificaram que os teores de nitrogênio e fósforo decresceram durante o período de desenvolvimento das plantas; os teores de potássio apresentaram uma tendência irregular, isto é, houve um grande aumento no teor foliar de $\mathrm{K}$, do mês de abril a junho, que após decresceu acentuadamente até o mês de setembro. Os teores de cálcio e magnésio aumentaram gradativamente durante o período (abril a setembro). 
É sabido que o manejo da poda e da irrigação em figueiras pode ser utilizado com o objetivo de aumentar o período de oferta de figos no mercado, mas que o uso combinado dessas técnicas em algumas épocas do ano pode não trazer resultados favoráveis, dependendo da região produtora. Alguns fatores inerentes à fenologia da planta, bem como fatores climáticos, fitossanitários e também nutricionais são os principais condicionantes do processo produtivo em diferentes épocas.

Em virtude da existência de escassas informações sobre a nutrição da figueira, principalmente condicionada a diferentes períodos de poda durante o ano, aliada a avaliação do estado nutricional sob manejo de irrigação, foi conduzido o presente experimento onde foram avaliados durante dois ciclos agrícolas, os teores nutricionais foliares e nos frutos de figueira em diferentes meses de poda, com e sem irrigação.

\section{Material e Métodos}

O trabalho foi conduzido em área experimental da Faculdade de Ciências Agronômicas da UNESP, Campus de Botucatu/SP. As coordenadas geográficas locais, de acordo com Tubelis e Salibe (1989) são: $22^{\circ} 52^{\prime} 47^{\prime \prime} \mathrm{S}, 48^{\circ} 25^{\prime} 12^{\prime}$ 'W e altitude de $810 \mathrm{~m}$. O tipo climático predominante no local é o temperado quente (mesotérmico), com chuvas no verão e seca no inverno (Cwa - Koppen). A temperatura média do mês mais frio (julho) é de $17,1^{\circ} \mathrm{C}$ e a do mês mais quente (fevereiro) de $23,3^{\circ} \mathrm{C}$, com precipitação média anual de $1.314 \mathrm{~mm}$ (MARTINS, 2004). O solo da área foi classificado como Nitossolo Vermelho, segundo os critérios da Empresa Brasileira de Pesquisa Agropecuária - EMBRAPA (1999).

A área total do experimento continha 420 plantas de figueira do cultivar Roxo de Valinhos, com 2 anos e 10 meses de idade no mês de Julho de 2004, quando foram iniciados os tratamentos com poda e irrigação. O espaçamento foi de $3 \mathrm{~m}$ entre linhas e $2 \mathrm{~m}$ entre plantas, representando uma densidade de 1660 plantas ha $^{-1}$. O resultado da análise química do solo antes da aplicação dos tratamento são apresentadas na Tabela 1. O solo foi calcareado e adubado conforme resultados de análises de solo prévias e seguindo as recomendações técnicas de Campo-Dall'Orto et al. (1996). Dessa maneira, foram efetivamente aplicados no ano de 2001: $500 \mathrm{~g}$ de superfosfato simples, $200 \mathrm{~g}$ de cloreto de potássio e $700 \mathrm{~g}$ de sulfato de amônio por planta, parcelados em 2 vezes nos meses de agosto e outubro. Posteriormente, aplicaram-se 500 gramas de esterco de galinha curtido por planta, também parcelado em 2 vezes, nos meses de dezembro/2002 e janeiro/2003. Após a instalação, as plantas seguiram recebendo adubações anuais, tanto químicas como orgânicas, conforme as recomendações técnicas e uma produtividade esperada menor que $10 \mathrm{t} \mathrm{ha}^{-1}$.

Tabela 1. Características químicas do solo onde foi realizado o experimento, após a elevação da saturação por bases e adubação de plantio. Área experimental do Departamento de Produção Vegetal/FCA/UNESP/Botucatu. Setembro/2001.

\begin{tabular}{|c|c|c|c|c|c|c|c|c|c|c|c|}
\hline pH & M.O. & $\mathbf{P}_{\text {resina }}$ & $\mathbf{A l}^{+3}$ & $\mathbf{H}+\mathbf{A l}$ & $\mathbf{K}$ & $\mathbf{C a}$ & Mg & SB & CTC & V\% & $\mathbf{S}$ \\
\hline \multicolumn{4}{|c|}{$\mathrm{CaCl}_{2} \mathrm{~g} / \mathrm{dm}^{3} \mathrm{mg} / \mathrm{dm}^{3}$} & \multicolumn{8}{|c|}{$-------------\mathrm{mmol}_{\mathrm{c}} / \mathrm{dm}^{3}--------------$} \\
\hline 5,6 & 31 & 14 & --- & 32 & 1,3 & 37 & 21 & 60 & 91 & 66 & -- \\
\hline
\end{tabular}

Fonte: Laboratório de Fertilidade do Solo - setor de Ciências do Solo, Departamento de Recursos Naturais. FCA/ UNESP/Botucatu, 2007. 
Os tratamentos consistiram em quatro diferentes épocas de poda (julho, agosto, setembro e outubro) associadas ou não a irrigação, quando necessário. A condução do experimento foi realizada nos ciclos agrícolas 2004 e 2005.

O delineamento experimental foi o de parcelas subdivididas, com 5 repetições em blocos, onde as parcelas corresponderam aos tratamentos com e sem irrigação e as subparcelas foram constituídas pelas podas realizadas nos meses de julho, agosto, setembro e outubro dos anos de 2004 e 2005 . Foram utilizadas 10 plantas por parcela experimental, das quais somente as 5 centrais foram consideradas úteis (PIMENTEL GOMES, 1990).

As características avaliadas foram teores de nitrogênio, fósforo, potássio, cálcio, magnésio, enxofre, cobre, boro, ferro, zinco e manganês nas folhas e nos frutos de figueira em dois ciclos agrícolas de produção.

Para isso, amostras de folhas foram retiradas nos meses de dezembro de 2004 e 2005, correspondentes aos tratamentos com poda nos meses de julho e agosto e nos meses de janeiro de 2005 e 2006 amostras correspondentes aos tratamentos com poda nos meses de setembro e outubro, com o objetivo de avaliar os efeitos das diferentes épocas e da irrigação complementar, no teor nutricional foliar da figueira. Para compor as amostragens foram coletadas folhas completas em estádio de plena floração (dezembro e janeiro), recém maduras, da porção média do ramo, nos diferentes lados da planta, com boa exposição ao sol (HERNANDEZ et al., 1991). As amostras foram retiradas de três plantas por repetição do bloco, embora a parcela experimental tenha sido composta de cinco plantas úteis. Foram coletadas quatro folhas de cada planta, totalizando 12 folhas por unidade experimental (ou parcela). Como havia cinco repetições em blocos, foram empregadas 60 folhas por tratamento avaliado no experimento. Após a coleta, as folhas foram lavadas e secas conforme a metodologia proposta por Sarruge e Haag (1974).
Para análise dos teores de nutrientes nos frutos também foram retiradas amostras de três plantas por repetição do bloco, coletando-se quatro frutos por planta. Cada amostra foi constituída de 12 frutos por unidade experimental (ou parcela), totalizando 60 frutos por tratamento avaliado, sendo que os mesmos foram coletados no estádio final da maturação (fevereiro), para os tratamentos correspondentes a poda realizada nos meses de julho e agosto. A exceção ocorreu com os meses de setembro e outubro de 2004 e 2005, onde os frutos foram coletados em abril, mês em que teve início a colheita do figo maduro. A lavagem dos frutos seguiu o mesmo procedimento recomendado para as folhas. As análises laboratoriais foram efetuadas de acordo com o método proposto por Malavolta, Vitti e Oliveira (1997) e realizadas no Laboratório de Nutrição Mineral de Plantas do Departamento de Recursos Naturais da FCA/UNESP/Botucatu.

Os tratamentos fitossanitários e o manejo de plantas daninhas foram feitos na medida em que se fizeram necessários, seguindo as recomendações de Penteado e Franco (1997). As plantas foram podadas com a finalidade de adquirirem a conformação de 6 ramos produtivos (RIGITANO, 1964; PENTEADO; FRANCO, 1997). Os 6 ramos foram cortados a cerca de $10-15 \mathrm{~cm}$ acima da base e em seguida, procedeu-se ao pincelamento dos cortes com pasta bordalesa. Iniciada a brotação, executaram-se desbrotas periódicas, para deixar em cada um dos três ramos adultos, apenas dois brotos vigorosos e bem colocados.

Os dados meteorológicos foram fornecidos pelo Departamento de Recursos Naturais da referida Faculdade. $\mathrm{O}$ balanço hídrico da área experimental está apresentado nas Figuras 1, 2 e 3 e os dados de temperaturas máxima, média e mínima na Figura 4. 


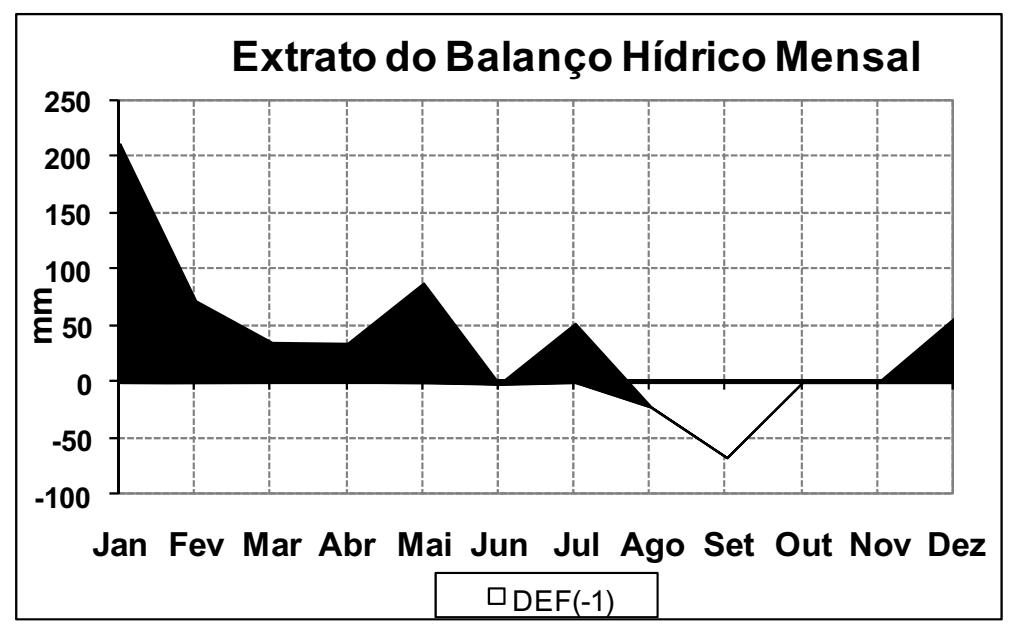

Figura 1. Balanço hídrico do ano de 2004. FCA/UNESP/Botucatu, 2007.

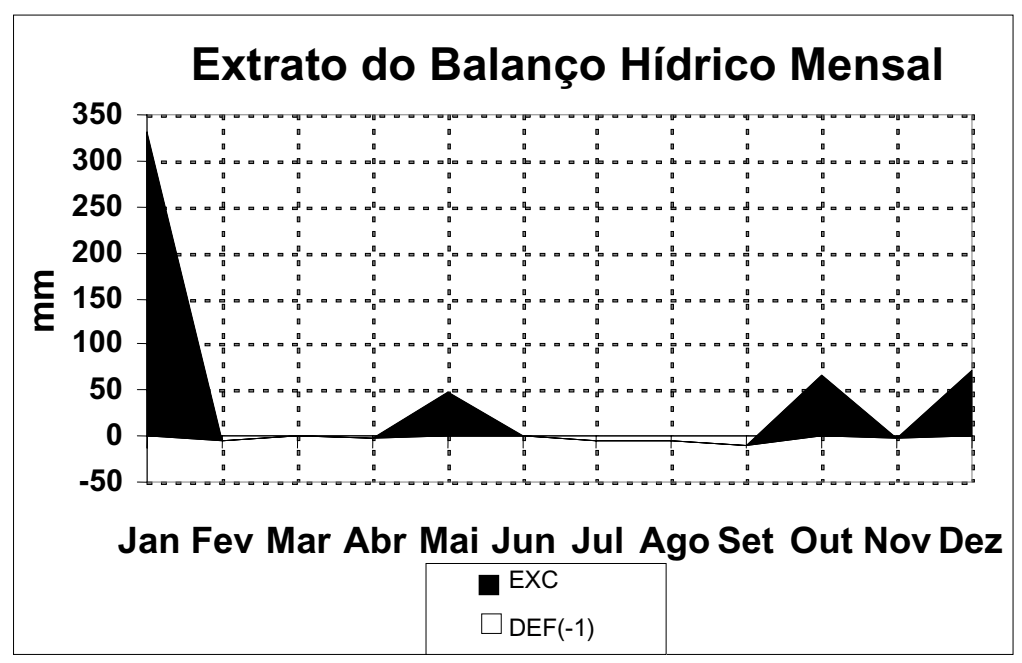

Figura 2. Balanço hídrico do ano de 2005. FCA/UNESP/Botucatu, 2007.

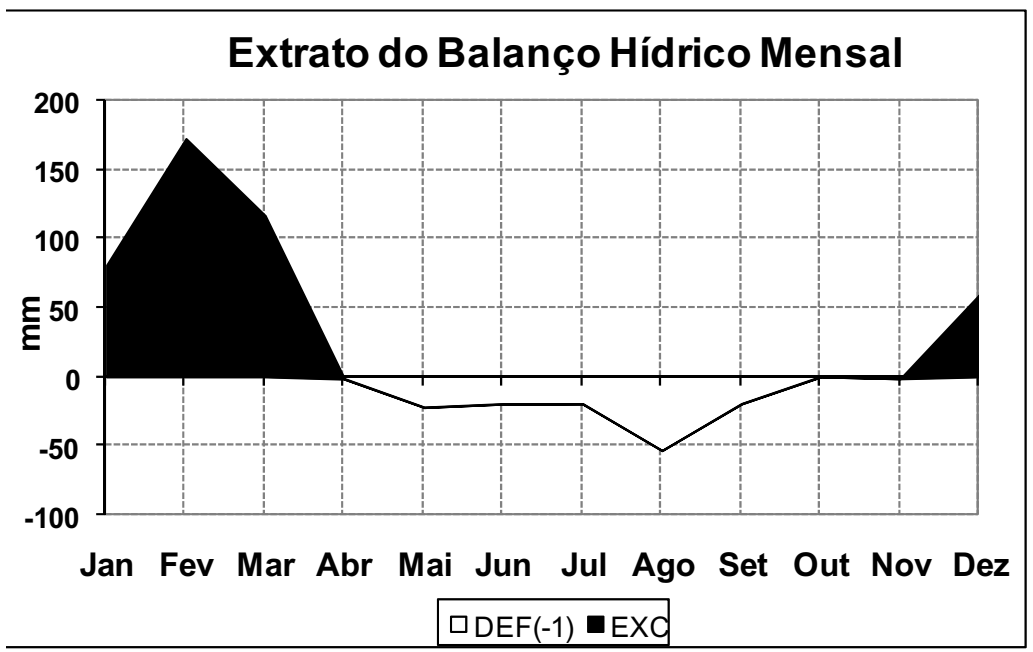

Figura 3. Balanço hídrico do ano de 2006. FCA/UNESP/Botucatu, 2007. 


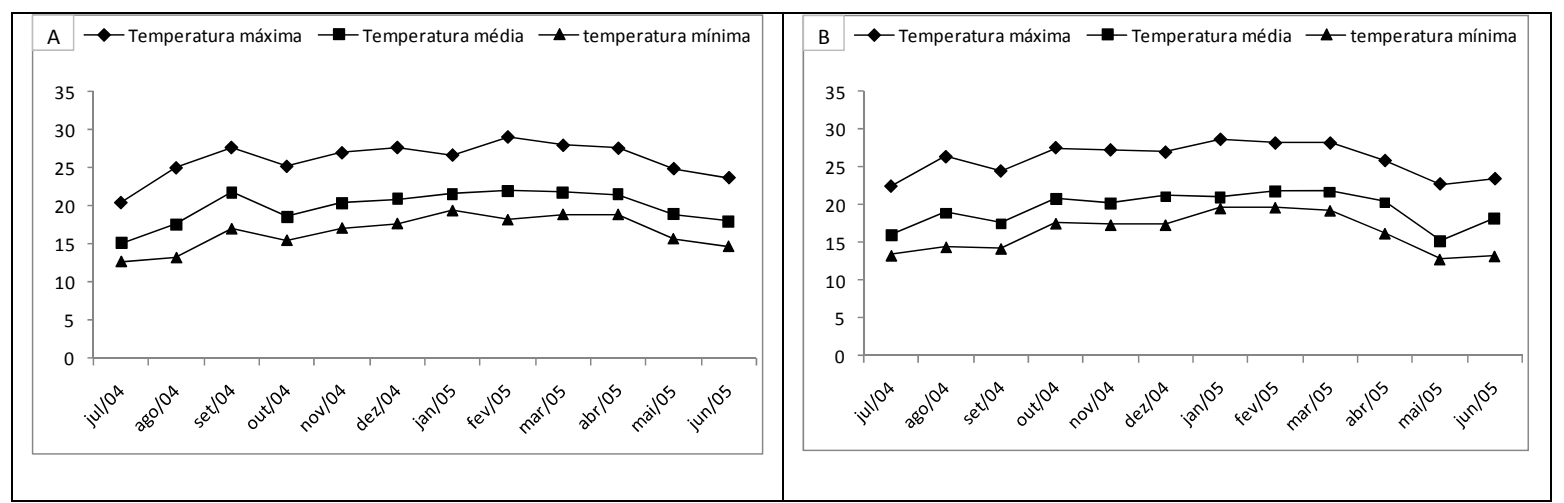

Figura 4. Médias mensais das temperaturas máxima, média e mínima $\left({ }^{\circ} \mathrm{C}\right)$ nos ciclos de 2004/05 (A) e 2005/06 (B) medidas durante os meses de realização do experimento. FCA/UNESP/Botucatu. 2007.

O sistema de irrigação utilizado foi o gotejamento localizado sob a copa. A freqüência das irrigações baseou-se em dados de evaporação coletados através do Tanque Classe A, que foi instalado na área experimental. As lâminas de irrigação aplicadas corresponderam às quantidades necessárias para satisfazer $100 \%$ da evapotranspiração de referência (ETo) do tanque classe A. O momento das irrigações foi determinado em função da reposição da água evaporada no tanque.

Determinou-se a evapotranspiração de referência (ETo) por meio da seguinte equação:

\section{ETo $=$ Kp x ECA}

Onde:

ETo = evapotranspiração de referência

$\mathrm{Kp}=$ Coeficiente do tanque classe A. Seguindo as recomendações de Hernandez (1999), adotou-se o Kp de 0,75.

$\mathrm{ECA}=$ evaporação do tanque classe A (mm)

A determinação da evapotranspiração da cultura (Etc) foi calculada pela seguinte equação:

\section{Etc $=$ Kc x Eto}

Onde:

Etc $=$ evapotranspiração da cultura

$\mathrm{Kc}=$ coeficiente de cultivo. Adotou-se o Kc de 0,47, o qual foi encontrado por Olitta, Sampaio e Barbin (1979).

Eto $=$ evapotranspiração de referência
Foram instalados gotejadores para cada planta do experimento e a vazão média dos mesmos foi de $2,34 \mathrm{~L} \mathrm{~h}^{-1}$. Os cálculos da necessidade de reposição de água para a cultura foram efetuados semanalmente, a partir da coleta dos dados do tanque classe A. A quantidade de água aplicada, semanalmente, foi determinada em função do balanço entre a evaporação e a precipitação do período. Detectada a necessidade de suplementação de água para a cultura, bem como a quantidade a ser aplicada, foi estabelecido o número de horas em que o equipamento deveria ficar funcionando.

\section{Resultados e Discussão}

\section{A-Teores nutricionais foliares}

Os resultados obtidos evidenciaram que não houve diferenças significativas entre os teores de macro e micronutrientes nas folhas nos tratamentos com e sem irrigação no ciclo 2004/05, com exceção do cobre, cujo tratamento com irrigação apresentou maior teor do elemento (6 $\left.\mathrm{mg} \mathrm{kg}^{-1}\right)$ (Tabela 2). Em relação aos meses de poda, foram verificadas diferenças significativas para os teores de $\mathrm{Ca}, \mathrm{Fe}$, $\mathrm{Cu}$ e $\mathrm{Zn}$ (Tabela 3). 
Tabela 2. Teores de macro e micronutrientes nas folhas e frutos da figueira submetida a tratamentos com ou sem irrigação. Ciclo 2004/05.

\begin{tabular}{cccccccccccc}
\hline Irrigação & $\mathrm{N}$ & $\mathrm{P}$ & $\mathrm{K}$ & $\mathrm{Ca}$ & $\mathrm{Mg}$ & $\mathrm{S}$ & $\mathrm{B}$ & $\mathrm{Cu}$ & $\mathrm{Fe}$ & $\mathrm{Mn}$ & $\mathrm{Zn}$ \\
\hline \multicolumn{10}{c}{$\mathrm{g} \mathrm{kg}^{-1}$} \\
\hline \multicolumn{10}{c}{} & \multicolumn{10}{c}{ Folha } \\
\hline COM & 35 & 3,1 & 20 & 13 & 5 & 1,5 & 31 & $6 \mathrm{~A}$ & 75 & 117 & 43 \\
SEM & 34 & 2,8 & 20 & 12 & 4 & 1,8 & 29 & $4 \mathrm{~B}$ & 76 & 111 & 44 \\
Média & 34 & 2,9 & 20 & 13 & 5 & 1,6 & 30 & 5 & 76 & 114 & 43 \\
DMS & 4,8 & 1,3 & 1,5 & 1,7 & 1,3 & 0,8 & 3,5 & 0,5 & 9,7 & 9,7 & 7,8 \\
\hline & 19 & 3,0 & 17 & 5 & 2 & 0,9 & 28 & 4 & 34 & 46 & $28 \mathrm{~A}$ \\
\hline COM & 19 & 2,5 & 16 & 5 & 2 & 0,9 & 27 & 5 & 30 & 37 & 20 B \\
SEM & 19 & 2,8 & 16 & 5 & 2 & 0,9 & 27 & 4 & 32 & 42 & 24 \\
Média & 19 & 1,2 & 3,4 & 0,2 & 0,1 & 0,1 & 8,5 & 3,1 & 3,6 & 8,6 & 1,7 \\
DMS & 1,3 & 1,2 &
\end{tabular}

Médias seguida de letras diferentes na coluna diferem entre si pelo teste Tukey $(P \leq 0,05)$.

Tabela 3. Teores de macro e micronutrientes nas folhas e frutos da figueira submetida a épocas de poda. Ciclo 2004/05.

\begin{tabular}{|c|c|c|c|c|c|c|c|c|c|c|c|}
\hline Irrigação & $\mathrm{N}$ & $\mathrm{P}$ & $\mathrm{K}$ & $\mathrm{Ca}$ & $\mathrm{Mg}$ & $\mathrm{S}$ & $\mathrm{B}$ & $\mathrm{Cu}$ & $\mathrm{Fe}$ & $\mathrm{Mn}$ & $\mathrm{Zn}$ \\
\hline & \multicolumn{6}{|c|}{$\mathrm{g} \mathrm{kg}^{-1}$} & \multicolumn{5}{|c|}{ mg kg-1 } \\
\hline \multicolumn{12}{|c|}{ Folha } \\
\hline Julho & 33 & 3,1 & 20 & $13 \mathrm{AB}$ & 5 & 1,7 & 27 & $6 \mathrm{~A}$ & $78 \mathrm{~A}$ & 110 & $41 \mathrm{~B}$ \\
\hline Agosto & 34 & 2,7 & 20 & $11 \mathrm{~B}$ & 5 & 1,8 & 32 & $5 \mathrm{AB}$ & $71 \mathrm{~B}$ & 116 & $38 \mathrm{~B}$ \\
\hline Setembro & 35 & 3,0 & 20 & $14 \mathrm{~A}$ & 4 & 1,6 & 32 & $4 \mathrm{BC}$ & $76 \mathrm{AB}$ & 129 & $48 \mathrm{~A}$ \\
\hline Outubro & 36 & 2,9 & 21 & $13 \mathrm{AB}$ & 4 & 1,5 & 30 & $4 \mathrm{C}$ & $78 \mathrm{AB}$ & 100 & $47 \mathrm{~A}$ \\
\hline Média & 34 & 2,9 & 20 & 13 & 5 & 1,6 & 30 & 5 & 76 & 114 & 43 \\
\hline DMS & 3,5 & 0,5 & 1,9 & 2,6 & 0,9 & 0,4 & 5,3 & 1,1 & 6,5 & 38 & 5,8 \\
\hline \multicolumn{12}{|c|}{ Fruto } \\
\hline Julho & $17 \mathrm{~B}$ & 2,7 & $16 \mathrm{~B}$ & $6 \mathrm{~B}$ & 2 & 0,9 & 27 & $3 B$ & $35 \mathrm{~A}$ & $54 \mathrm{~A}$ & $27 \mathrm{~A}$ \\
\hline Agosto & $17 \mathrm{~B}$ & 2,9 & $16 \mathrm{~B}$ & $5 \mathrm{~A}$ & 2 & 0,9 & 27 & $4 B$ & $33 \mathrm{~A}$ & $49 \mathrm{~A}$ & $29 \mathrm{~A}$ \\
\hline Setembro & $21 \mathrm{~A}$ & 2,8 & $16 \mathrm{AB}$ & $4 \mathrm{~A}$ & 2 & 0,9 & 29 & $4 \mathrm{AB}$ & $35 \mathrm{~A}$ & $36 \mathrm{AB}$ & $24 \mathrm{AB}$ \\
\hline Outubro & $21 \mathrm{~A}$ & 2,5 & $18 \mathrm{~B}$ & $5 \mathrm{~A}$ & 2 & 0,9 & 26 & $7 \mathrm{~A}$ & $25 \mathrm{~B}$ & $28 \mathrm{~B}$ & $18 \mathrm{~B}$ \\
\hline Média & 19 & 2,8 & 16 & 5 & 2 & 0,9 & 27 & 4 & 32 & 42 & 24 \\
\hline DMS & 3,1 & 0,4 & 1,6 & 0,4 & 0,5 & 0,1 & 9,2 & 2,5 & 5,0 & 21 & 6,4 \\
\hline
\end{tabular}

Médias seguida de letras diferentes na coluna diferem entre si pelo teste Tukey $(P \leq .0,05)$.

A análise da interação entre as épocas de poda e a irrigação, no ciclo 2004/05, mostrou haver diferenças significativas para os teores de cálcio ( $\mathrm{F}$ $=4,18)$, ferro $(F=5,50)$ e zinco $(F=7,10)$ nas folhas e para os teores de cálcio $(\mathrm{F}=22,75)$, potássio $(\mathrm{F}=$ $3,94)$, enxofre $(F=4,98)$ e magnésio $(F=3,97)$ nos frutos (Tabela 4). 
Tabela 4. Teores de nutrientes nas folhas e frutos da figueira submetida a épocas de poda com e sem irrigação. Ciclo 2004/05.

\begin{tabular}{|c|c|c|c|c|c|}
\hline \multirow[b]{2}{*}{ Irrigação } & \multicolumn{5}{|c|}{ Épocas de poda } \\
\hline & $\begin{array}{l}\text { Julho } \\
\text { Ca folha }\end{array}$ & Agosto & Setembro & Outubro & Média \\
\hline Com & $15 \mathrm{Aa}$ & $10 \mathrm{Ab}$ & $14 \mathrm{Aa}$ & $13 \mathrm{Aab}$ & 13 \\
\hline Sem & $11 \mathrm{Bb}$ & $12 \mathrm{Aab}$ & $14 \mathrm{Aa}$ & $13 \mathrm{Aab}$ & 13 \\
\hline \multirow[t]{2}{*}{ Média } & 13 & 11 & 14 & 13 & \\
\hline & Ca fruto & & & & \\
\hline Com & $5,5 \mathrm{Aa}$ & $4,2 \mathrm{Bb}$ & $4,3 \mathrm{Ab}$ & $5,4 \mathrm{Aa}$ & 4,8 \\
\hline Sem & $5,9 \mathrm{Aa}$ & 5,2 Aab & 4,6 Abc & $4,1 \mathrm{Bc}$ & 4,9 \\
\hline \multirow[t]{2}{*}{ Média } & 5,7 & 4,7 & 4,4 & 4,7 & \\
\hline & $\underline{\text { Kfruto }}$ & & & & \\
\hline Com & $15 \mathrm{Ab}$ & $16 \mathrm{Aab}$ & $17 \mathrm{Aab}$ & $19 \mathrm{Aa}$ & 17 \\
\hline Sem & $16 \mathrm{Aa}$ & $15 \mathrm{Aa}$ & $15 \mathrm{Aa}$ & $17 \mathrm{Aa}$ & 16 \\
\hline \multirow[t]{2}{*}{ Média } & 16 & 16 & 16 & 18 & \\
\hline & $\mathrm{Mg}$ fruto & & & & \\
\hline Com & $2,0 \mathrm{Ab}$ & $2,0 \mathrm{Ab}$ & $2,1 \mathrm{Aab}$ & $2,7 \mathrm{Aa}$ & 2,2 \\
\hline Sem & $2,0 \mathrm{Aa}$ & $2,2 \mathrm{Aa}$ & $2,5 \mathrm{Aa}$ & $2,0 \mathrm{Ba}$ & 2,2 \\
\hline \multirow[t]{2}{*}{ Média } & 2,0 & 2,1 & 2,3 & 2,3 & \\
\hline & S fruto & & & & \\
\hline Com & $\overline{0,9 \mathrm{Aa}}$ & $0,9 \mathrm{Aa}$ & $0,9 \mathrm{Aa}$ & $0,9 \mathrm{Aa}$ & 0,9 \\
\hline Sem & $0,9 \mathrm{Aa}$ & $0,9 \mathrm{Aab}$ & $0,9 \mathrm{Aa}$ & $0,8 \mathrm{Bb}$ & 0,9 \\
\hline \multirow[t]{2}{*}{ Média } & 0,9 & 0,9 & 0,9 & 0,85 & \\
\hline & Fe folha & & & & \\
\hline Com & $80 \mathrm{Aa}$ & $65 \mathrm{Ab}$ & $76 \mathrm{Aa}$ & $79 \mathrm{Aa}$ & 75 \\
\hline Sem & $77 \mathrm{Aa}$ & $77 \mathrm{Aa}$ & $75 \mathrm{Aa}$ & $76 \mathrm{Aa}$ & 76 \\
\hline \multirow[t]{2}{*}{ Média } & 78 & 71 & 76 & 78 & \\
\hline & Zn folha & & & & \\
\hline Com & $39 \mathrm{Ab}$ & $35 \mathrm{Ab}$ & $53 \mathrm{Aa}$ & $44 \mathrm{Aab}$ & 43 \\
\hline Sem & $43 \mathrm{Aa}$ & $41 \mathrm{Aa}$ & $43 \mathrm{Ba}$ & $50 \mathrm{Aa}$ & 44 \\
\hline \multirow[t]{2}{*}{ Média } & 41 & 38 & 48 & 47 & \\
\hline & Zn fruto & & & & \\
\hline Com & $27 \mathrm{Aab}$ & $33 \mathrm{Aa}$ & $31 \mathrm{Aa}$ & $22 \mathrm{Ab}$ & 28 \\
\hline Sem & $27 \mathrm{Aa}$ & $24 \mathrm{Bab}$ & $16 \mathrm{Bbc}$ & $14 \mathrm{Bc}$ & 20 \\
\hline Média & 27 & 29 & 24 & 18 & \\
\hline
\end{tabular}

Médias seguidas de letras diferentes, maiúscula na coluna e minúsculas na linha, exceto para as médias que são na linha, diferenciam entre si pelo teste Tukey $(P \leq 0,05)$.

No ciclo agrícola 2005/06, nos tratamentos com e sem irrigação, houve diferenças para o nitrogênio (40 $\left.\mathrm{g} \mathrm{kg}^{-1}\right)$ e o potássio $\left(20 \mathrm{~g} \mathrm{~kg}^{-1}\right)$, cujos maiores teores foram verificados no tratamento com irrigação (Tabela 5). Tal fato possivelmente possa ser explicado pela maior absorção dos elementos através do fluxo de massa, favorecido pela maior quantidade de água.
Sobre os teores nutricionais adequados em folhas de figueira existem poucos trabalhos, mas as referências são maiores que nos frutos. Teixeira e Carvalho (1978) efetuaram um estudo bibliográfico, com o objetivo de levantar subsídios relativos à nutrição mineral da figueira e confirmaram sobre a existência de poucos estudos, em relação à nutrição dessa cultura. Como conclusão do trabalho os autores 
reportaram que as concentrações de nitrogênio nítrico e total, fósforo, potássio, cálcio e magnésio avaliados nas folhas de figueiras, variam durante o ano agrícola. Tanto o nitrogênio nítrico como o total, dosados nas folhas de figueira, mostraram-se como indicadores do estado de nutrição da cultura. Entretanto o emprego do método como processo de recomendação não pode ser adotado, em função dos poucos experimentos existentes.

Da mesma maneira que o reportado pelos autores supracitados, no presente experimento, os teores de nitrogênio nas folhas variaram no ciclo agrícola 2005/06, em função dos meses do ano em que foi realizada a poda (Tabela 6), sendo os maiores teores observados nos meses correspondentes a poda realizada em setembro e outubro, quando foram verificados fatores mais propícios ao crescimento das plantas, isto por que as condições de temperaturas e hídricas observadas no decorrer do experimento indicam aumento nas temperaturas médias e balanço hídrico mais favorável, notadamente a partir de setembro, respectivamente (Figuras 1, 2, 3 e 4).

Tabela 5. Teores de macro e micronutrientes nas folhas e frutos da figueira submetida a tratamentos com ou sem irrigação. Ciclo 2005/06.

\begin{tabular}{|c|c|c|c|c|c|c|c|c|c|c|c|}
\hline Irrigação & $\mathrm{N}$ & $\mathrm{P}$ & $\mathrm{K}$ & $\mathrm{Ca}$ & $\mathrm{Mg}$ & $\mathrm{S}$ & B & $\mathrm{Cu}$ & $\mathrm{Fe}$ & $\mathrm{Mn}$ & $\mathrm{Zn}$ \\
\hline & \multicolumn{6}{|c|}{$\mathrm{g} \mathrm{kg}^{-1}$} & \multicolumn{5}{|c|}{$\mathrm{mg} \mathrm{kg-1}$} \\
\hline \multicolumn{12}{|c|}{ Folha } \\
\hline $\mathrm{COM}$ & $40 \mathrm{~A}$ & 2,8 & $20 \mathrm{~A}$ & 17 & 4 & 2,4 & 38 & 6 & 56 & 111 & 71 \\
\hline SEM & $37 \mathrm{~B}$ & 2,6 & $15 \mathrm{~B}$ & 19 & 4 & 2,0 & 32 & 10 & 53 & 103 & 67 \\
\hline Média & 38 & 2,7 & 17 & 18 & 4 & 2,2 & 35 & 8 & 54 & 107 & 69 \\
\hline DMS & 2,4 & 0,3 & 2,3 & 9,4 & 0,6 & 0,5 & 9,3 & 3,7 & 11,2 & 16,0 & 13,6 \\
\hline \multicolumn{12}{|c|}{ Fruto } \\
\hline $\mathrm{COM}$ & $19 \mathrm{~B}$ & 2,4 & 18 & 4 & 2 & 0,9 & 22 & 3 & 34 & 38 & 30 \\
\hline SEM & $21 \mathrm{~A}$ & 2,4 & 17 & 4 & 2 & 0,9 & 24 & 5 & 35 & 31 & 28 \\
\hline Média & 20 & 2,4 & 17 & 4 & 2 & 0,9 & 23 & 4 & 34 & 34 & 29 \\
\hline DMS & 0,8 & 0,5 & 7,4 & 0,5 & 1,3 & 0,3 & 4,6 & 4,6 & 12,3 & 11,0 & 6,2 \\
\hline
\end{tabular}

Médias seguida de letras diferentes na coluna diferem entre si pelo testeTukey $(P \leq 0,05)$.

Nas mesmas condições edafoclimáticas onde foi realizado o presente ensaio, Brizola et al. (2005a) realizaram experimento com o objetivo de avaliar o estado nutricional da figueira 'Roxo de Valinhos', submetida a níveis crescentes de potássio. Os autores concluíram que as diferenças observadas nos teores de macronutrientes nas folhas, tanto no decorrer da estação de crescimento das plantas (meses), como também entre anos agrícolas consecutivos, poderiam ser atribuídas às diferenças de estádios fisiológicos da planta, além das práticas de adubações, das condições de disponibilidade de água e das condições de temperaturas.

Segundo Mengel e Kirkby (1987), a umidade do solo influencia no suprimento de nutrientes, especificamente para o fósforo e potássio. Conforme Hernandez et al. (1994), as diminuições nos teores foliares de $\mathrm{P}, \mathrm{Mg}$ e $\mathrm{K}$ também estão ligadas a condições de déficit hídrico.

As Tabelas 3, 4 e 5 demonstraram que em relação aos teores de nitrogênio nas folhas, independentemente dos tratamentos avaliados, os mesmos foram superiores aos padrões apresentados por Quaggio, Raij e Piza Júnior (1996), não apresentando limitações para o crescimento das plantas e para a produção de frutos. O trabalho de Quaggio, Raij e Piza Júnior (1996) relata os padrões foliares para a figueira como sendo: $\mathrm{N}=20-25 ; \mathrm{P}=$ $1-3 ; \mathrm{K}=10-30 ; \mathrm{Ca}=30-50 ; \mathrm{Mg}=7,5-10 ; \mathrm{S}=1,5-3$ $\mathrm{g} \mathrm{kg}^{-1}$ e $\mathrm{B}=30-75 ; \mathrm{Cu}=2-10 ; \mathrm{Fe}=100-300 ; \mathrm{Mn}=$ 100-350; $\mathrm{Mo}=-, \mathrm{Zn}=50-90 \mathrm{mg} \mathrm{kg}^{-1}$.

Com isso, ficou evidenciado que os teores nutricionais foliares apresentados no presente 
trabalho estavam em níveis considerados adequados para a figueira com exceção do cálcio e magnésio, em que os teores encontraram-se abaixo do padrão, nos dois ciclos agrícolas avaliados. Embora as plantas não tenham apresentado sintomas visuais de deficiência dos mesmos, esse fato pode estar relacionado a sintomas de fome oculta. A deficiência de cálcio e magnésio está intimamente relacionada com o crescimento e desenvolvimento das plantas.

Nessa linha de pesquisa, Pedrotti, Manica e Beltrame (1983), ao avaliarem níveis de irrigação, crescimento das plantas e concentração de nutrientes nas folhas de figueira 'Roxo de Valinhos', também não observaram diferenças nos teores foliares dos nutrientes $\mathrm{N}, \mathrm{P}, \mathrm{K}, \mathrm{Ca}$ e $\mathrm{Mg}$, durante o período de crescimento vegetativo, sob tratamentos correspondentes a lâminas crescentes de irrigação.

Hernandez et al. (1994) desenvolveram pesquisa sobre os efeitos de níveis de nitrogênio e da irrigação na cultura da figueira e concluíram que, o teor de nitrogênio nas folhas de figueira não apresentou diferenças significativas entre os tratamentos irrigado e não irrigado, o que confirma os dados deste ensaio no ciclo 2004/05 (Tabela 2). Já no ciclo 2005/06 os teores foram significativamente maiores no tratamento com irrigação (Tabela 5).

Com relação aos teores de micronutrientes, o cobre, manganês e boro estavam na faixa considerada adequada, ou muito próximos a ela (HAAG et al., 1979). Já os teores de ferro nos dois ciclos agrícolas e os de zinco, no ciclo agrícola 2004/05, apresentaram-se inferiores aos limites reportados por Quaggio, Raij e Piza Júnior (1996), em todos os meses de poda, com e sem irrigação. Foram procuradas possíveis explicações para tal ocorrência na análise de solos, porém a mesma encontrava-se nos padrões normais (Tabela 1). Com isso, atribuiu-se ao fato de que na época em que foram realizadas as amostras foliares, esses nutrientes já tivessem sido translocados para os frutos, porque nos mesmos, os teores apresentaramse acima dos teores considerados adequados para a figueira (Tabela 3).
A ordem de exportação de macronutrientes pelas folhas de figueira foi de $\mathrm{N}>\mathrm{K}>\mathrm{Ca}>\mathrm{Mg}>\mathrm{P}>\mathrm{S}$ no ciclo 2004/05 enociclo 2005/06 foide $\mathrm{N}>\mathrm{Ca}>\mathrm{K}>\mathrm{Mg}>\mathrm{P}>\mathrm{S}$. Para os micronutrientes foi de $\mathrm{Mn}>\mathrm{Fe}>\mathrm{Zn}>\mathrm{B}>\mathrm{Cu}$ no ciclo 2004/05 e de $\mathrm{Mn}>\mathrm{Zn}>\mathrm{Fe}>\mathrm{B}>\mathrm{Cu}$ no ciclo 2005/06 (Tabelas 2 e 5).

\section{$B$ - Teores nutricionais nos frutos}

Resultados sobre a absorção e a exportação de nutrientes pelos frutos da figueira foram apresentados por Hiroce, Olima e Gallo (1979). De acordo com tais resultados, os macronutrientes predominantes nos frutos são: nitrogênio e potássio, enquanto que, dentre os micronutirentes, o molibdênio foi o elemento encontrado nos frutos na concentração mais baixa (inferior a $1 \mathrm{mg} \mathrm{kg}^{-1}$ ). $\mathrm{O}$ cobre foi o micronutriente encontrado em maior concentração nos frutos. Os padrões encontrados pelos autores supracitados são: $\mathrm{N}=10,3 ; \mathrm{P}=1,55 ; \mathrm{K}=13 ; \mathrm{Ca}=$ 3,$6 ; \mathrm{Mg}=1,0, \mathrm{~S}=0,95 \mathrm{~g} \mathrm{~kg}^{-1} ; \mathrm{Cu}=50,6 ; \mathrm{Mn}=10$; $\mathrm{B}=23 ; \mathrm{F}=25$ e $\mathrm{Zn}=8,6 \mathrm{mg} \mathrm{kg}^{-1}$.

Os resultados dos teores nutricionais apresentados no presente trabalho (Tabelas 2, 3, 4, 5 e 6 ) foram comparados com os padrões relatados pelo trabalho pioneiro de Hiroce, Olima e Gallo (1979), com a finalidade de detectarem-se possíveis deficiências ou excessos de nutrientes nos frutos, ocasionadas pelas épocas de poda e pela irrigação complementar. Tais resultados indicaram que em média, para todos os macro e micronutrientes, independentemente da época de poda e do uso ou não de irrigação complementar, os teores estavam na faixa considerada adequada ou até superior. A exceção foi para o cobre que apresentou-se em níveis bem abaixo dos relatados pelos autores supracitados.

Contrariamente, os teores de zinco e manganês foram muito superiores aos padrões reportados, mesmo considerando que os dados foram obtidos na mesma época de amostragem, recomendada por Hiroce, Olima e Gallo (1979) e por Hernandez et al. (1991). É importante ressaltar que o trabalho 
de Hiroce, Olima e Gallo (1979) foi realizado em solução nutritiva, o que pode dificultar a comparação com os teores obtidos em campo.

No ciclo 2004/05 não houve diferenças significativas entre os tratamentos com e sem irrigação, com exceção do zinco, que apresentou os maiores teores $\left(28 \mathrm{mg} \mathrm{kg}^{-1}\right)$ com irrigação. $\mathrm{O}$ nitrogênio apresentou diferença significativa e o maior teor foi observado sem irrigação $\left(21 \mathrm{~g} \mathrm{~kg}^{-1}\right)$ (Tabela 2).

O presente trabalho corrobora com o trabalho de Hernandez, Lemos Filho e Buzetti (1992), realizado em condições de campo, em que os nutrientes exigidos em maior quantidade pelos frutos da figueira, tanto maduros quanto verdes, foram $\mathrm{N}$ e $\mathrm{K}$ (Tabelas 2 e 5)

Com relação aos meses de poda, os resultados demonstraram que no ciclo 2004/2005, os teores de $\mathrm{Ca}, \mathrm{K}, \mathrm{Mg}, \mathrm{S}$ e $\mathrm{Zn}$ apresentaram valores que diferiram estatísticamente, conforme o emprego da irrigação (Tabela 2). No ciclo 2005/06 houve diferenças para os teroes de $\mathrm{N}, \mathrm{Ca}$, e $\mathrm{Cu}$ (Tabela5).

Fachinello, Manicae Machado(1979) salientaram que devido às poucas pesquisas sobre a exigência da figueira em elementos nutritivos, não existem regras especiais a esse respeito. As conclusões do trabalho efetuado são de que o nitrogênio em excesso provoca desenvolvimento vigoroso e frutos maiores, porém retarda a maturação dos mesmos. Os autores não encontraram diferenças significativas quanto a produção total de figos verdes, sob adubação com dois níveis de nitrogênio, fósforo e potássio, em figueira cultivar João Pedro.

Num segundo trabalho sobre o mesmo tema, Brizola et al. (2005b) avaliaram a exportação de macronutrientes pelos ramos e frutos de plantas de figueira. As avaliações foram realizadas nos ramos das podas de inverno e nos frutos, durante o período de produção. Ocorreram diferenças significativas para as exportações de macronutrientes nos ramos e frutos, sendo que estas se deram exclusivamente pelo efeito da maior produção de massa seca nos tratamentos com níveis superiores de potássio, onde as maiores quantidades foram exportadas pelos frutos. A ordem de exportação de macronutrientes pelos frutos e ramos foi $\mathrm{N}>\mathrm{K}>\mathrm{Ca}>\mathrm{Mg}>\mathrm{P}>\mathrm{S}$, respectivamente.

Neste ensaio a ordem de exportação de macronutrientes pelos frutos foi a mesma descrita por Brizola et al. (2005b), nos dois ciclos agrícolas. Em relação aos micronutrientes foi de $\mathrm{Mn}>\mathrm{Fe}>\mathrm{Zn}>\mathrm{B}>\mathrm{Cu}$ no ciclo 2004/05 e $\mathrm{Mn}=\mathrm{Fe}>\mathrm{Zn}>\mathrm{B}>\mathrm{Cu}$ no ciclo 2005/06 (Tabela 6).

Tabela 6. Teores de macro e micronutrientes nas folhas e frutos da figueira submetida a épocas de poda. Ciclo 2005/06.

\begin{tabular}{|c|c|c|c|c|c|c|c|c|c|c|c|}
\hline Irrigação & $\mathrm{N}$ & $P$ & $\mathrm{~K}$ & $\mathrm{Ca}$ & $\mathrm{Mg}$ & $\mathrm{S}$ & B & $\mathrm{Cu}$ & $\mathrm{Fe}$ & $\mathrm{Mn}$ & $\mathrm{Zn}$ \\
\hline & \multicolumn{6}{|c|}{$\mathrm{g} \mathrm{kg}^{-1}$} & \multicolumn{5}{|c|}{ mg kg-1 } \\
\hline \multicolumn{12}{|c|}{ Folha } \\
\hline Julho & $37 \mathrm{C}$ & 3,0 & 17 & $21 \mathrm{~A}$ & 4 & 2,4 & 39 & $10 \mathrm{~A}$ & 55 & 105 & $72 \mathrm{AB}$ \\
\hline Agosto & $38 \mathrm{BC}$ & 2,7 & 18 & $20 \mathrm{AB}$ & 4 & 2,2 & 37 & $6 \mathrm{~B}$ & 55 & 117 & $67 \mathrm{AB}$ \\
\hline Setembro & $39 \mathrm{AB}$ & 2,7 & 17 & $15 \mathrm{~B}$ & 4 & 2,1 & 35 & $7 \mathrm{AB}$ & 53 & 98 & $75 \mathrm{~A}$ \\
\hline Outubro & $40 \mathrm{~A}$ & 2,6 & 18 & $15 \mathrm{~B}$ & 4 & 2,1 & 30 & $9 \mathrm{AB}$ & 54 & 110 & $63 \mathrm{~B}$ \\
\hline Média & 38 & 2,7 & 17 & 18 & 4 & 2,2 & 35 & 8 & 54 & 107 & 69 \\
\hline DMS & 1,4 & 0,6 & 2,0 & 5,7 & 0,5 & 0,5 & 4,1 & 3,7 & 14,5 & 36 & 10,7 \\
\hline \multicolumn{12}{|c|}{ Fruto } \\
\hline Julho & $18 \mathrm{~B}$ & 2,3 & $16 \mathrm{~B}$ & $3 \mathrm{~B}$ & 2 & 0,9 & 23 & $2 \mathrm{~B}$ & 36 & $32 \mathrm{~B}$ & 30 \\
\hline Agosto & $19 \mathrm{AB}$ & 2,3 & $17 \mathrm{AB}$ & $4 \mathrm{AB}$ & 2 & 0,9 & 24 & $4 \mathrm{~A}$ & 32 & $49 \mathrm{~A}$ & 30 \\
\hline Setembro & $20 \mathrm{AB}$ & 2,6 & $18 \mathrm{AB}$ & $4 \mathrm{AB}$ & 2 & 0,9 & 22 & $5 \mathrm{~A}$ & 32 & $31 \mathrm{~B}$ & 30 \\
\hline Outubro & $22 \mathrm{~A}$ & 2,4 & $19 \mathrm{~A}$ & $4 \mathrm{~A}$ & 2 & 0,9 & 23 & $5 \mathrm{~A}$ & 38 & $25 \mathrm{~B}$ & 27 \\
\hline Média & 20 & 2,4 & 17 & 4 & 2 & 0,9 & 23 & 4 & 34 & $34 \mathrm{~B}$ & 29 \\
\hline DMS & 3,6 & 0,7 & 2,7 & 0,8 & 0,4 & 0,3 & 3,2 & 1,9 & 12,3 & 15,0 & 8,4 \\
\hline
\end{tabular}

Médias seguida de letras diferentes na coluna diferem entre si pelo testeTukey $(P \leq 0,05)$. 


\section{Conclusão}

Frente ao exposto, foi possível concluir que no âmbito geral da avaliação, o levantamento nutricional das folhas e dos frutos, realizado no período de avaliação do experimento, não apresentou limitação de elementos nutrientes, para o crescimento e a produção das plantas de figueira, em diferentes meses de poda e presença ou ausência de irrigação complementar. Contudo, para as folhas, foram observados teores abaixo do padrão para o cálcio e o magnésio.

\section{Agradecimentos}

À FAPESP - Fundação de Amparo à Pesquisa do Estado de São Paulo, pelo auxílio financeiro concedido. Processo 03/13766-0

\section{Referências}

ANTUNES, L. E. C.; ABRAHÃO, E.; SILVA, V. J. Caracterização da cultura da figueira no estado de Minas Gerais. Informe Agropecuário, Belo Horizonte, v. 18, n. 188, p. 43-44, 1997.

BRIZOLA, R. M. O.; LEONEL, S.; TECCHIO, M. A.; DA HORA, R. C. Teores de macronutirentes em pecíolos e folhas de figueira (Ficus carica, L.) em função da adubação potássica. Ciência e Agrotecnologia, Lavras, v. 29, n. 3, p. 610-616, 2005a.

BRIZOLA, R. M.; LEONEL, S.; TECCHIO, M. A.; MISCHAN, M. M. Exportação de macronutrientes pelos ramos e frutos da figueira cultivada em função da adubação potássica. Acta Scientiarum Agronomy, Maringá, v. 27, n. 1, p. 33-37, 2005 b.

CAMPO-DALL'ORTO, F. A.; CANTARELA, H.; RAIJ, B. V.; PIZA JÚNIOR, C. T. Frutas de clima temperado: II. Figo, maçã, marmelo, pêra e pêssego em pomar compacto. In: RAIJ, B. V.; CANTARELA, H.; QUAGGIO, J. A.; FURLANI, A. M. C. (Ed.). Recomendações de adubação e calagem para o Estado de São Paulo. 2. ed. Campinas: Instituto Agronômico e Fundação IAC, 1996. p. 139140.

CORRÊA, L. S.; SANTOS, S. C. Condução e tratos culturais da figueira. In: CORRÊA, L. S.; BOLIANI, A. C. Cultura da figueira: do plantio à comercialização. Ilha Solteira: FUNEP/FAPESP, 1999. p. 51-68.
EMPRESA BRASILEIRA DE PESQUISA AGROPECUÁRIA - EMBRAPA.. Centro Nacional de Pesquisa de Solos. Sistema brasileiro de classificação de solos. Rio de Janeiro: EMBRAPA/CNPT, 1999.

FACHINELLO, J. C.; MANICA, I.; MACHADO, A. A. Resposta da figueira (Fícus carica L.) cv. São Pedro a dois níveis de adubação com nitrogênio, fósforo e potássio. In: CONGRESSO BRASILEIRO DE FRUTICULTURA, 5., 1979, Pelotas. Anais... Pelotas: Sociedade Brasileira de Fruticultura, 1979. p. 889-895.

FERNANDES, F. M.; BUZETTI, S. Fertilidade do solo e nutrição da figueira. In: CORREAA, L. S.; BOLIANI, A.C. Cultura da figueira: do plantio à comercialização. Ilha Solteira: FUNEP/FAPESP, 1999. p. 69-85.

HAAG, H. P.; OLIVEIRA, G. D.; ROCHA FILHO, J. V. C.; SILVA, D. H. Distúrbios nutricionais em figueira (Ficus carica L.) cultivada em solução nutritiva. $O$ solo, Piracicaba, v. 71, n. 1, p. 31-34, 1979.

HERNANDEZ, F. B. T.; CORRÊA, L. S.; MODESTO, J. C.; YOKOTA, M. A. Efeitos de níveis de nitrogênio e da irrigação na cultura do figo. Revista Brasileira de Fruticultura, Cruz das Almas, v. 13, n. 4, p. 211-216, 1991.

HERNANDEZ, F. B. T.; LEMOS FILHO, M. A. F.; BUZETTI, S. Efeitos de lâminas de irrigação e níveis de nitrogênio sobre os principais parâmetros produtivos da cultua do figo (Fícus carica L.). In: CONGRESSO BRASILEIRO DE ENGENHARIA AGRÍCOLA, 21., 1992. Anais... Santa Maria: Sociedade Brasileira de Engenharia Agrícola, 1992. v. 2 "B”, p. 875-885.

HERNANDEZ, F. B. T.; SUZUKI, M. A.; BUZETTI, S.; CORREAA, L. S. Resposta da figueira ao uso da irrigação e nitrogênio na região de Ilha Solteira. Scientia Agrícola, Piracicaba, v. 51, n. 1, p. 99-104, 1994.

HERNANDEZ, F. B. T. Irrigação na figueira. In: CORRÊA, L. S.; BOLIANI, A. C. Cultura da figueira do plantio à comercialização. Ilha Solteira: FUNEP, 1999. p. $87-113$.

HIROCE, R.; OLIMA, M.; GALLO, J. R. Composição mineral e exportação de nutrientes pelas colheitas de frutos subtropicais e temperados. In: CONGRESSO BRASILEIRO DE FRUTICULTURA, 5., 1979, Pelotas. Anais... Pelotas: Sociedade Brasileira de Fruticultura, 1979. p. 179-189.

MAIORANO, J. A.; ANTUNES, J. E. C.; REGINA, M. A.; ABRAHÃO, E.; PEREIRA, A. F. Botânica e caracterização de cultivares de figueira.. Informe Agropecuário, Belo Horizonte, v. 18, n. 188, p. 22-24, 1997. 
MALAVOLTA, E.; VITTI, G. C.; OLIVEIRA, S. A. Avaliação do estado nutricional das plantas: princípios e aplicações. 2. ed. Piracicaba: Associação Brasileira de Potassa e do Fosfato, 1997.

MARTINS, D. Botucatu é realmente a cidade dos bons ares. Jornal da Faculdade de Ciências Agronômicas, Botucatu, p. 2-3, abr. 2004.

MENGEL, K.; KIRKBY, E. A. Principles of plant nutrition. 4. ed. Bern: International Potash Institute, 1987.

OLITTA, A. F. L.; SAMPAIO, V. R.; BARBIN, D. Estudo da lâmina e freqüência de irrigação por gotejo na cultura do figo. O Solo, Piracicaba, v. 71, n. 2, p. 9-22, 1979.

PEDROTTI, E. L.; MANICA, I.; BELTRAME, L. F. S. Níveis de irrigação, crescimento das plantas e concentração de nutrientes nas folhas de figueira (Fícus carica L.) 'Roxo de Valinhos'. Agronomia Sulriograndense, Porto Alegre, v. 19, n. 1, p. 103-116, 1983.

PENTEADO, S. R. Cultura da figueira. In: PENTEADO, S. R. Fruticultura de clima temperado em São Paulo. Campinas: Fundação Cargill, 1986. p. 113-129.

PENTEADO, S. R.; FRANCO, J. A. M. Figo (Ficus carica L.). Manual técnico das culturas. Campinas: SAA/ CATI/DCT, 1997.
PIMENTEL GOMES, F. Curso de estatística experimental. 13. ed. Piracicaba: Nobel, 1990.

PROEBSTING, E. L.; WARNER, R. M. The effect of fertilizers on yield, quality and leaf composition of figs. Porceedings of American Society for Horticultural Science, Alexandria, v. 63, n. 1, p. 10-13, 1954.

QUAGgIO, J. A.; RAIJ, B. V.; PIZA JÚNIOR., C. T. Frutíferas: amostragem de folhas e diagnose foliar. In: RAIJ, B. V.; CANTARELA, H.; QUAGGIO, J. A.; FURLANI, A. M. C. (Ed.). Recomendações de adubação e calagem para o Estado de São Paulo. 2. ed. Campinas: Instituto Agronômico, 1996. p. 123-125.

RIGITANO, O. Instruções para a cultura da figueira. Campinas: SAA/IAC, 1964. v. 3, p. 344-362. (Boletim Técnico, 146). Mimeografado.

SARRUGE, J. R.; HAAG, H. P. Análises químicas em plantas. Piracicaba: ESALQ/USP, 1974.

TEIXEIRA, N. T.; CARVALHO, L. H. Alguns aspectos nutricionais da cultura da figueira (Fícus carica, L.). Ecossistema, Espírito Santo do Pinhal, v. 3, n. 1, p. 5-7, 1978.

TUBELIS, A.; SALIBE, A. A. Relações entre produção de laranjeira 'Hamlin' e as precipitações mensais no altiplano de Botucatu. Pesquisa Agropecuária Brasileira, Brasília, v. 24, n. 7, p. 801-806, 1989. 
